\title{
INNOVATIONS AMONG PEOPLE. HOW POSITIVE RELATIONSHIPS AT WORK CAN TRIGGER INNOVATION CREATION
}

\author{
Aldona Glińska-Neweś, Agata Sudolska, Arkadiusz Karwacki, \\ Joanna Górka
}

\section{Introduction}

Nowadays it is more and more frequently emphasized that organization's ability to innovate is an explanatory factor in determining its competitiveness. It refers to the fact that contemporary organizations act under permanent pressure of economic, technological, political and social changes. Taking into account such an unstable environment, the issue that becomes significant is enhancing organizational capacity to respond to external changes with some novel products, processes, ideas etc. (Nonaka \& Takeuchi, 1995; Bessant, Lamming, Noke, \& Philips, 2005; Bessant \& Tidd, 2007; Ellonen, Blomqvist, \& Puumalainen, 2008; Pietrzak \& Łapińska, 2015).

An innovation is a very wide and multidimensional concept. The present-day approach suggests that an innovation is every result of human activities contributing to the improvement of human life quality; every activity which enables one to act better, more efficiently, more effectively. Such results may include new or improved products and technologies, new ways of service provision, new standards of products and services or activities which distinguish one organization from the other (Damanpour, 1996; Bessant \& Tidd, 2007; Baregheh, Rowley, \& Sambrook, 2009).

With the increasing popularity of the issues concerning the necessity for being innovative to strengthen and develop all kinds of modern organizations, the conditions that promote the emergence and implementation of innovations have also become the subject of reflection. Nowadays we have already known that innovations do not emerge by leaps, in a spontaneous way. There is a considerable agreement among researchers on the fact that innovations emerge within organizations as a consequence of building inside them the 'healthy' organizational culture and the climate that promotes creative thinking and acting (Burke \& Litwin, 1992; Ekvall, 1996; NaranjoValencia, Jimenez-Jimenez \& Sanz-Valle, 2011; Wolf, Kaudela-Baum, \& Meissner, 2012; Mitrović, Grubić-Nešić, Milisavljević, Melović, \& Babinková, 2014).

Such climate supportive of innovations is a specific combination of elements connected with manners of communication within the organization, positive interpersonal exchange, organizational integration, the employee sense of safety, co-participation and co-operation of the workers, support for creative ideas, openness and trust existent in the organization, the organization's dynamism and attitude to diversity (Isaksen, Lauer, Ekval, \& Britz, 2001; Loewe \& Dominiquini, 2006; Isaksen, \& Ekvall, 2010). Among aforementioned factors, in the light of growing research movement towards positive processes in organizations (Positive Organizational Scholarship; Cameron, Dutton, \& Quinn, 2003) we focus our attention on positive relationships at work. Additionally, together with theories proving the importance of the debate dimension in innovation climate we include in our analysis the elements of internal communication in the organization.

The aim of our paper is to present the role of positive relationships at work and communication facets in stimulation innovations emergence in an organization. As our assumption is that positive relationships at work are highly associated with openness and trust among employees, in the empirical part of the paper we focus on relations between positive employee relationships, informal meetings, open internal communication and individual commitment to innovation. As the outcome of the research conducted in 200 companies we develop a model of relationships between aforementioned variables. Contributing to the existing theory on the innovation climate our findings provide also useful managerial 
implications concerned with enhancing employees activities and commitment to creating innovations.

\section{Theoretical Background \\ 1.1 Innovations and Innovation Climate in Organizations}

Innovation is always coupled with change due to the fact that organizations use innovations in order to respond the changes in their internal and external environment or to take pre-emptive action focused on influencing the environment. So we can say that innovation is any change in different areas of the organization activity, that introduces progress compared to the existing state, developed in or outside the organization as a response to some signaled needs or satisfying the needs that have previously had been unrevealed (Damanpour, 1996; Brown \& Ulijn, 2004). Innovation may include a wide range of change types, depending on organizational resources, capabilities, strategies or requirements. The present day approach involves a variety of innovations, starting from product and process innovations, passing through organizational and market innovations and ending with social innovations (Damanpour, 1996; Bessant \& Tidd, 2007; Plessis, 2007).

As highlighted by Baregheh, Rowley and Sambrook (2009) who have conducted a comprehensive analysis of several innovation definitions (extracted from a number of different disciplines), innovation is a multi-stage process in which organizations transform their ideas into new or improved products, processes in order to advance, compete and differentiate themselves successfully in the market (Baregheh et al., 2009). Additionally, it has been recognized that creating innovation is a continuous process occurring among people, consisting of the worker participation and the interaction among them (Agrell \& Gustafson, 1996; Van Offenbeek \& Koopman, 1996; Drach-Zahavy \& Somech, 2001, Szczepańska-Woszczyna, 2014). Innovation is also described as intentional introduction and application within a group or organization of ideas, processes, products or procedures, new to the relevant unit of adoption, designed to significantly benefit the individual, the group, the organization or the society (West \& Farr, 1990; De Dreu, 2006). Such approach suggests that an innovation only has to be something new to the relevant unit of adoption, and innovation in one team or organization may be common practice in other teams or organizations (De Dreu, 2006). This means that innovation is not a domain of a selected group of outstandingly creative and talented people; instead every employee may contribute to the innovation by improving specific elements of the everyday work. This leads us to the necessity for focus on all employees' engagement and willingness to improve their ways of performing and procedures and products being outcomes of their work in order to achieve organizational progress and development. Therefore, it is of significant importance to create the climate that supports all employees' innovativeness.

The reference literature presents a variety of models and approaches to explore the role of the organizational climate. As highlighted by several authors, organizational climate has been recognized as a key determinant of enterprise's capability for creating innovations (see Burke \& Litwin, 1992; Woodman, Sawyer, \& Griffin, 1993; Ekvall, 1996; Naranjo-Valencia et al., 2011; Wolf, Kaudela-Baum \& Meissner, 2012). The organizational climate is understood as an organizational reality, a property of the organization containing recurring patterns of behavior, attitudes and feeling that characterize the life in an organization (Isaksen et al., 2001; Isaksen \& Ekvall, 2010). The climate for creativity and change promotes the creation, consideration and use of new products, services and ways of working. It supports the development, assimilation and utilization of new and different approaches and concepts (Isaksen et al., 2001). There are a number of variables which are considered as the crucial components of the organizational climate favorable to innovations (Loewe \& Dominiquini, 2006; Hunter, Bedell, \& Mumford, 2007; Isaksen \& Ekvall, 2010; Mitrović, Grubić-Nešić, Milisavljević, Melović \& Babinková, 2014). In spite of the fact that there are different typologies of the main dimensions of the organizational climate supporting innovations, we refer to those proposed by Isaksen et al. (2001) who focus on the following aspects: employees challenge and involvement, freedom, trust/openness of employees, time used for elaborating new ideas, playfulness and humor, presence of conflict, idea support, employees debating and risk-taking which means tolerance for uncertainty and ambiguity in the workplace. 
Having to bear in mind that organizational climate favourable to innovations is a multidimensional issue, we focus on the trust/ openness dimension and we relate it to communication between employees and their interpersonal relationships as prerequisites for enhancing organization employee activities concerned with innovations. Relationships at work and communication facets have been proved as crucial for creating a context in which innovations can be not only initiated but also maintained in the organization (Hunter et al., 2007; Mumford, Hunter, Eubanks, Bedell \& Murphy, 2007; Isaksen \& Ekvall, 2010), however studies concerning relations linking all these variables are still limited. Moreover, we are inspired by the positive theory in management emphasizing the importance of positive relationships at work which will be explained in the paragraph 1.3.

\subsection{Internal Communication Contribution to Openness/Trust Dimension of Innovation Climate}

As highlighted by several authors, effective internal communication has a positive impact on generating innovations within an organization as it facilitates dispersion of ideas as well as increases their amount and diversity. This in turn results in cross-fertilization of several ideas. Moreover it has been recognized that it creates an internal environment favorable to the survival of these new ideas in the organization (Aiken \& Hage, 1971; Ross, 1974; Damanpour, 1991; Leenders, Van Engelen \& Kratzer, 2003; De Dreu, 2006; Holá, 2012). Interestingly, the association of the variables concerning internal communication within organization is not linear and, for instance, e-mail information exchange has an U-shape relationship with team creativity. For this reason various facets of organizational communication still have to be explored and analysed within the construct of climate supporting innovativeness. In our approach we focus on two variables, i.e. internal communication including sharing both the good and bad information, and an opportunity for employee informal meetings during workinghours. Such selection of control variables is motivated by the fact, that they are related to both positive relationships and innovativeness.

Employee openness refers to the issue of mutual trust and emotional safety in interpersonal relationships. While there is a high degree of trust between people in the organization, they can be genuinely open and frank with one another, sharing both good and bad information (Isaksen et al., 2001). On the other hand, interpersonal trust concerns the predictability of people's behavior (Serva, Fuller \& Mayer, 2005; Hardin, 2006), it stems from a communication system. While employees are communicating frequently and openly, it stimulates the emergence of trust between them, because due to mutual understanding it makes it easier to predict each other's behavior. In such internal environment employees count on each other for any kind of support, they are willing to share knowledge and expertise with others. The high level of trust within an organization has many beneficial effects, such as: the increase of organizational flexibility, increase of speed of operations, creating positive employee attitudes, enabling transfer of knowledge and expertise, enabling creativity and innovation, employee loyalty and increase in their motivation (Shaw, 1997; Dirks \& Ferrin, 2001; Colquitt, Scott, \& LePine, 2007). Besides, trust conveys optimism of the future, people's positive attitude as well as their goodwill (Lewicki \& Bunker, 1996; McKnight \& Chervany, 2001; Pirson, 2008), what is necessary to create willingness and readiness for innovations.

With the regard to the importance of communication in shaping organizational climate supporting innovations, it is extremely important to point out the debate dimension. According to Isaksen et al. (2001), this variable concerns an occurrence of encounters and disagreements between viewpoints, ideas and experiences of employees. In an organization focusing on debating different voices are heard and people are keen on putting forward their ideas for consideration and review. In fact, in a climate supportive of innovations everyone has a right to express their own opinion. Moreover, employees discuss opposing opinions and thus share a diversity of perspectives. For creating such stimulating environment it is necessary to give the employees a sense of security and introduce transparent incentive system appreciating their initiative and rewarding their participation in the innovation process (see Anderson \& West, 1998; Leiponen, 2005; Loewe \& Dominiquini, 2006; Hunter et al., 2007; Isaksen et al., 2001, Isaksen \& Ekval, 2010; Szczepańska-Woszczyna, 2014). 
Another significant issue concerning the creation of the pro-innovative organizational climate is encouraging employees to seek and discover unconventional and non-standard ways of performing their tasks and achieving goals (Szczepańska-Woszczyna, 2014). One of the stimulators for employee innovative thinking is to allow informal meetings within an organization. They let individuals share their knowledge in a supportive work environment and are accompanied with positive socioemotional interactions and signals of relational commitment (Gorse \& Emmitt, 2009). It is quite frequent that during informal meetings employees deal with job-related issues. In such meetings they search for knowledge or opinions of their colleagues to confirm or reinforce their own ideas concerning the decision they have to make (Mangrum, 2002). This, in turn, strengthens their interpersonal relationships and emotional safety which contributes to trust/ openness dimension contained in the creative climate construct (Isaksen \& Ekvall, 2010). Moreover, from the innovation perspective an organization may benefit from informal meetings, as they allow employees to share the ideas that may not be fully developed yet. When employees feel free to meet and talk in the workplace, very often they spend time together on solving particular problems concerned with their tasks. This, in fact, stimulates them to search for several innovative solutions and may result in some novelty within organization.

Concerning that in our approach we operationalize trust/openness dimension with both internal communication and employee interpersonal relationships, we need to refer also to task and relationship conflicts as organizational behavior facets influencing the team innovativeness. Although a meta-analysis of the published and unpublished works (De Dreu \& Weingart, 2003) shows a moderately negative correlation between task conflict and overall team effectiveness, task conflict may be beneficial for team member ability to learn, to develop and implement new insights or solve complex problems, such as innovations (De Dreu, 2006). Some level of conflict may trigger team creativity through exposure of minority opinions and increase of individual courage to resist group conformity, which exemplifies openness/trust dimension (Nemeth \& Chies, 1988). Simultaneously, negative effects of task conflict on general team performance may be reduced by moderators, such as team climate, norms regarding conflict, and trust (De Church \& Marks, 2001). The moderating role of these elements, particularly in the process of innovation creation, was confirmed by Zhou and George (2001) who found that help and support from work-group colleagues influenced the creativity of employees dissatisfied with their jobs who actively responded to this situation (i.e. the group support turned dissatisfaction into creativity through a voice expression).These findings lead our attention to the relationships at work as antecedents of innovation creation. Additionally, their role in the process is interesting and still unclear. As, according to De Dreu (2006), task and relationship conflicts are moderately correlated, while relationship conflict is not significantly related to innovations, we decided to adopt a perspective opposite to conflict-innovation link, i.e. the perspective of positive relationships at work.

\subsection{Positive Relationships at Work and Their Role in Innovation Creation}

Various relationships, bonds and connections are the building blocks of every organization and organizations arrange the relationships between the individuals (Aydin \& Ceylan, 2009). In modern organizations the jobs, roles, and tasks are even more socially embedded than before, due to the growing interdependence and interactions with coworkers and service recipients. This leads scholars to the development of relational perspective (Grant \& Parker, 2009) suggesting that the real work of the human organization occurs within the space of interaction between its members (Bradbury \& Lichtenstein, 2000). Thus, the theorist must account for the relationships among, rather than the individual properties of, organizational members.

Among the specified relationship categories the positive relationships at work (PRW) are receiving a growing attention in business studies (see Dutton \& Ragins, 2007; Turner de Tormes Eby \& Allen, 2012) and appear to be the important research subject under the umbrella concept of the Positive Organizational Scholarship (Cameron, Dutton, \& Quinn, 2003; Cameron \& Spreitzer, 2012). As the research issue these relationships may refer to dyads, both as the supervisory relationships (Bono \& Yoon, 2012) and the coworker exchanges (Halbesleben, 2012), and to teams (Chen \& Sharma, 2012). 
As positive relationships at work (PRW) are concerned by different disciplines (e.g. psychology, sociology, management) and on different levels (individual, team, organization) there is no single 'best' definition reflecting absolute consensus (Ragins \& Dutton, 2007, p. 8). They may be defined in terms of states and processes accompanied relationships, their quality or outcomes. Respectively, Roberts distinguishes positive relationships as these in which there is a true sense of relatedness and mutuality (Roberts, 2007, p. 31); Stephens, Heaphy and Dutton (2012, p. 386) focusing on high-quality connections (short-term, dyadic interactions) propose to rely on subjective experience of vitality and aliveness, positive regard, mutuality and positive physiological responses; according to Kahn (1990) positive relationships support the employee ability to engage in work.

It seems that the latter perspective, i.e. analyzing positive relationships at work through their outcomes, is particularly important in management studies. Being absolutely convinced about the significance of positive relationships at work for organizational performance we are aware of the doubts that arise among other scholars and business practitioners. Many managers perceive this kind of relationships as a threat and a source of distraction (Berman, West, \& Richter, 2002). Thus, research aimed at exploring positive outcomes of positive relationships at work may help to reduce this skepticism.

Positive relationships at work are considered as antecedents of many positive results for both individuals and organizations, while the former effect may be considered as stimulating for the latter. In the first group (i.e. individual effects), the cognitive, physiological and behavioral processes improving individual functioning have been identified (Stephens et al., 2012, p. 387; Sökmen, Bitmiş, \& Üner, 2015). They include, e.g. the increase of processing speed and working memory performance, salutary effects on individual cardiovascular, neuroendocrine and immune systems, or enhancement and enrichment of self-identity. At a team level, positive relationships at work create a feeling of psychological safety and trust, contributing to greater learning from failures (Carmeli, Brueller, \& Dutton, 2009) and the entrepreneurial behaviour (Abeyrathne \& Jayawardena, 2014). Employees creating positive connections with coworkers are more inclined to invest their energy in helping others (Chiaburu \& Harrison, 2008). That may explain why, when asked why they continued their work, even if they did not have to, employees often responded that it was due to the relationships they had developed with others (Halbesleben, 2012, p. 107).

Relationships at work give a meaning to what employees do in the organization (Makin, Cooper, \& Cox, 1996), thus they may shape various organizational processes, including the decision-making and communication flow (Kram \& Isabella, 1985; Rawlins, 1992). Regarding our research project and this presentation aim we are particularly concerned about the influence that positive relationships at work have on employee innovativeness. There is already evidence suggesting positive relationships at work impact knowledge management effectiveness, comprising of learning and experimentation enhancement (Davidson \& James, 2007) and knowledge sharing increase (Ibarra, 1993). Through their impact on an individual identity positive relationships at work make people more open to continued growth and development and provide a secure base for learning and experimenting; people learn more from one another, discover their sources of strengths, competence and added value at work, and can experiment with new skills or tasks (Roberts, 2007). Subsequently, there are studies proving that positive social relationships in teams enhance individual creativity (MunozDoyague \& Nieto, 2012). PRW facilitate also the constructive exchange of critical feedback and people are more likely to consider failures, criticism and negative feedback as opportunities to learn and improve. Combining these with the positive effect that PRW have on the energy that people feel (Quinn, 2007), the overall impact of positive relationships at work on innovation process in organizations seems very likely.

\subsection{Hypotheses}

Regarding all the aforementioned positive effects that PRW have on working environment, as well as their associations with mechanisms related to innovations, we hypothesize that positive relationships in the organization support individual commitment to innovation creation process, and propose:

Hypothesis 1: Positive relationships at work stimulate the innovation creation by employees regardless of their job description. 
At the same time, in the research stream doubting PRW stimulating role in the organization, there are works demonstrating possible negative effect of social relationships on individual creative work (Shalley, 1995; PerrySmith \& Shalley, 2003). According to them, individuals involved in positive relationships with co-workers may be distracted and unwilling to explore a wide range of environmental stimuli. Moreover, strong positive ties are developed between similar individuals, while weak ties may connect people with different point of view, interests and perspectives, triggering creativity. Weak connections provide also an access to a larger group of people and a greater quantity of information.

Considering this inconsistency of studies exploring PRW links to individual creativity and innovativeness we hypothesize a curvilinear relationship between employee positive relationships and innovation creation:

Hypothesis 2: At low and high level of relationship positivity individual activity in innovation creation is lower than at moderate levels of relationship positivity.

Regarding that openness/trust dimension of innovation climate refers to both positive relationships and internal communication and the both are considered as antecedents of organizational innovativeness, we propose to concern PRW as prerequisites of the process in the following hypotheses:

Hypothesis 3: Positive relationships at work stimulate internal communication facets supporting employee innovativeness.

\section{Method}

\subsection{Procedures and Participants}

The study was conducted by means of a survey using the technique of questionnaire-based Computer Assisted Telephone Interview (CATI) on the sample of 200 Polish companies. In each company we obtained information from a person involved in leading a team creating innovations in an organization. The respondents of the study were HR department managers $(35.5 \%)$, marketing department managers $(16.5 \%)$, specialists $(14 \%)$, and other persons in managerial positions (13.5\%), company directors $(4.5 \%)$, deputy directors or members of the board $(6.5 \%)$, or project specialists $(7.5 \%)$. The companies have been selected from two rankings including the most dynamically developing enterprises in Central Europe: 'Gazelles of Business' by Bonnier Business (Poland) and the 'Deloitte Technology Fast 50 in Central Europe'. We assumed that enterprises listed in these prestigious rankings achieved their high indicators of development, inter alia, through innovation creation. The investigated sample of 200 enterprises consisted of organizations from the sector of commerce (98 entities), industry (76 entities), services (57 entities), construction (29), IT (6), transportation (6), agriculture (9), energy and publishing (3 each). The investigated entities most frequently operate on the national market (as was declared by $46.5 \%$ of the entities), on the UE market (32.5\%), and on the global one $(13.5 \%)$. Only 15 of the enterprises operate solely on the local market $(7.5 \%$ of the sample).

The interviews were conducted in October 2014. The research assistants first phoned selected companies asking for a contact with a person involved in leading a team creating innovations. While making appointments with interviewees the research assistants sent them the questionnaire to allow for self-preparation. The interviews were conducted on the phone. The interviewers read out the questions and noted down the answers using a special computer script, in this case, the LimeSurvey.

\subsection{Measures}

In the study we used the questionnaire consisting of items specifically designed for this study. The reliability of scales has been confirmed with Cronbach alpha coefficient. The items were grouped in two sets: 1. the organization of the innovativeness process (variables inspired by Szczepanska-Woszczyna, 2014; $\alpha=.79$ ) including 'innovations are proposed by individual employees regardless of their position' which in the further analysis is treated as a manifestation of the individual commitment to innovations; 2 . the dimensions of the innovation climate related to employee relationships and internal communication (variables inspired by Isaksen \& Ekvall 2010; $\alpha=.81$ ), including items 'interpersonal relationships are generally positive' (in the analysis we use the abbreviation 'positive relationships'), 'all the information is communicated, both the good and bad' ('openness' as the abbreviation), 'during working-hours employees have opportunity for informal meetings' (the abbreviation is to the 
'time for informal meetings'). In each case, the respondents evaluated statements in the form of affirmative sentences with a scale ranging from $0-100 \%$ with $10 \%$ intervals $(0 \%$ meaning 'I totally disagree', and $100 \%$ - 'I totally agree').

\section{Results}

The descriptive statistics are given in Tab. 1. As shown, correlations are rather low but positive and statistically significant, with one exception, i.e. the correlation between openness and time for informal meetings. Individual commitment to innovations, measured in our case with the individual activity in proposing innovations, is associated with positive relationships in an organization and with variables related to the communication. The correlation coefficients confirm also that there are links between positive relationships and both the openness in communication and the time for informal meetings during working-hours, however, the correlation between openness and informal meetings is very low and non-significant proving the independence of these variables.

\section{Tab. 1: Means, standard deviations and correlations for the study variables}

\begin{tabular}{l|c|c|c|c|c|c}
\multicolumn{1}{c|}{ Variable } & $\mathbf{M}$ & SD & $\mathbf{1}$ & $\mathbf{2}$ & $\mathbf{3}$ & $\mathbf{4}$ \\
\hline 1. Individual commitment to innovations & 6.16 & 2.46 & & & & \\
\hline 2. Positive relationships & 8.48 & 1.18 & $.35^{* *}$ & & & \\
\hline 3. Openness & 6.73 & 1.81 & $.27^{* *}$ & $.39^{* *}$ & & \\
\hline 4. Time for informal meetings & 6.64 & 2.24 & $.17^{*}$ & $.29^{* *}$ & .04 & \\
\hline
\end{tabular}

Note: $N=193 ;{ }^{*} p<.05 ;{ }^{* *} p<.01$

Source: own

\section{Tab. 2: Regression of individual commitment to innovations on positive relationships}

\begin{tabular}{l|c|c|c|c|c|c}
\multirow{2}{*}{} & \multicolumn{5}{|c}{ Individual commitment to innovations } \\
\cline { 2 - 8 } & \multicolumn{2}{|c|}{ Model 1 } & \multicolumn{2}{c}{ Model 2 } & \multicolumn{2}{c}{ Model 3 } \\
\cline { 2 - 7 } & B & \multicolumn{1}{c}{ SE } & \multicolumn{1}{c}{ B } & \multicolumn{1}{c}{ SE } & \multicolumn{1}{c}{ B } & \multicolumn{1}{c}{ SE } \\
\hline Intercept & 2.604 & .806 & -.502 & 1.217 & 1.980 & 4.652 \\
\hline Step 1 (control variables) & & & & & & \\
\hline Openness & $.356^{* *}$ & .093 & $.225^{*}$ & .099 & $.224^{*}$ & .099 \\
\hline Time for informal meetings & $.174^{*}$ & .076 & .097 & .077 & .108 & .080 \\
\hline Step 2 (linear effect) & & & & & & \\
\hline Positive relationships & & & $.531^{* *}$ & .159 & -.121 & 1.191 \\
\hline Step 3 (quadratic effect) & & & & & & \\
\hline Positive relationships & & & & & .041 & .074 \\
\hline $\mathrm{R}^{2}$ & .097 & & .147 & & .149 & \\
\hline $\mathrm{F}$ & $10.290^{* *}$ & & $10.950^{* *}$ & & $8.260^{* *}$ & \\
\hline$\Delta \mathrm{R}^{2}$ & & & .050 & & .001 & \\
\hline$\Delta \mathrm{F}$ & & & $11.160^{* *}$ & & .310 & \\
\hline
\end{tabular}

Note: ${ }^{*} p<.05 ;{ }^{* *} p<.01$

Source: own

To test for the curvilinear effect proposed in Hypothesis 2 we used a hierarchical regression analysis. The item: 'innovations are proposed by individual employees regardless of their position' was the dependent variable. In the first step (Model 1), openness and time for informal 
meetings were inserted as control variables. A linear term for positive relationships was entered in the second step (Model 2) and in the third step (Model 3) the squared term for positive relationships was entered. The results are presented in Tab. 2.

The control variables in Model 1 explain a significant portion of the variance, i.e. variables related to the internal communication predict the individual commitment to innovations. The addition of the linear term for positive relationships in Model 2 gives a statistically significant effect, which means that positive relationships serve as the better predictor of the individual commitment to innovation than communication facets analyzed in our survey. This supports the notion that PRW should be regarded as the prerequisite of the whole process (hypothesized in H3). However, the significance of B-coefficients shows that PRW effect takes over particularly the impact of the time for informal meetings on the employee commitment to innovation, and it is less relevant in the case of open communication. In Model 3 the B-coefficient for positive relationships is negative and for the squared term it is positive, but the coefficients are non-significant in both cases.
These results support Hypothesis 1 stating that positive relationships at work stimulate the innovation creation by employees regardless of their job description. At the same time, there are no significant effects supporting Hypothesis 2 stating that at low and high level of relationship positivity individual activity in innovation creation is lower than at moderate levels of relationship positivity. Moreover, regardless the significance of the results, the curvilinear relation between the individual commitment to innovations and positive relationships has a different shape than we hypothesized. Fig. 1 gives the predicted effects on the basis of hierarchical regression and shows both the linear (significant) and curvilinear (non-significant) relationships of the analyzed variables.

In our approach we investigate if the causal effect of positive relationships on individual commitment to innovations is mediated by communication facets including communicating both the good and the bad things and employees opportunities to spend time on informal meetings. The results presented in Tab. 2 revealed that PRW are more relevant in explaining the process. Consequently, to verify Hypothesis 3 and to grasp particular

\section{Fig. 1: Linear (significant) and curvilinear (non-significant) relation between individual commitment to innovations and employee positive relationships}

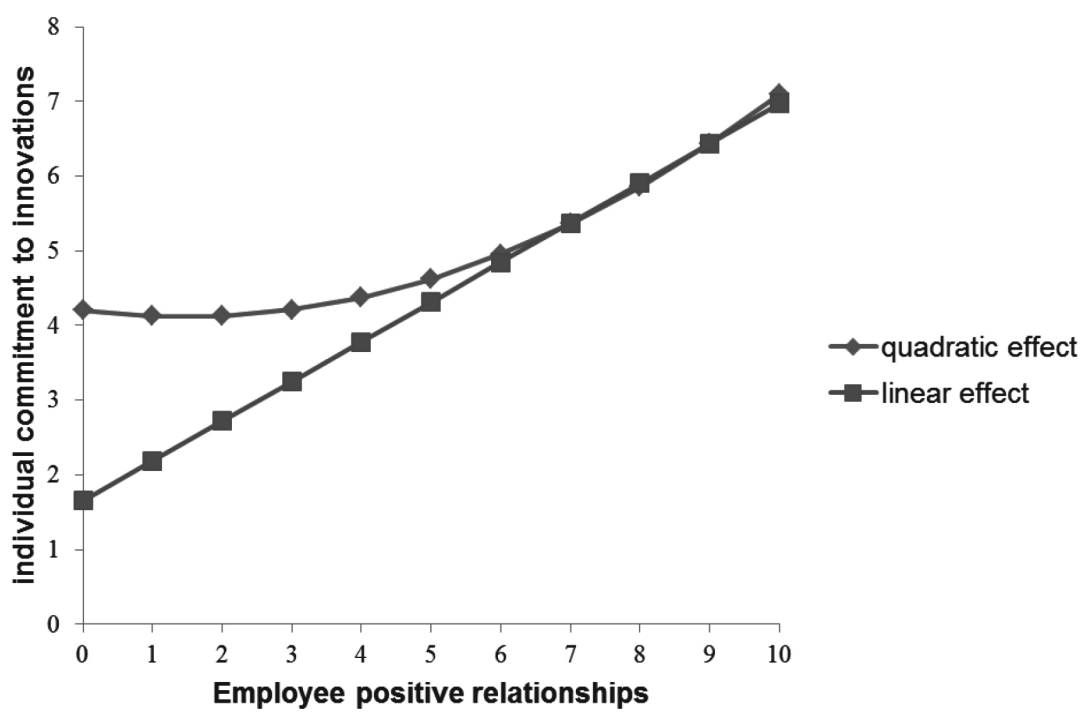




\section{Fig. 2. Positive employee relationships, informal meetings, internal communication and individual commitment to innovation - model of relationships}

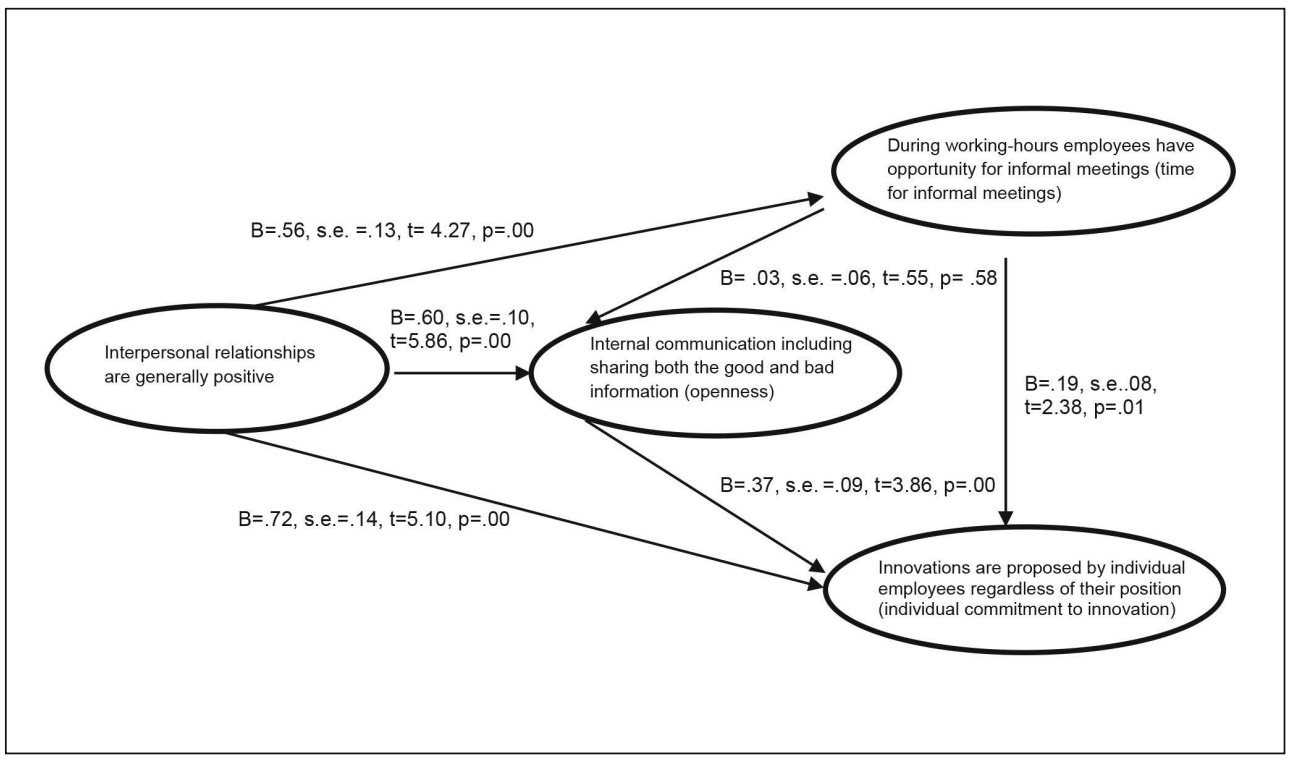

Source: own

links among all analyzed variables we used the linear regression analysis. Fig. 2 summarizes the model of these relationships in a path diagram.

Except for one link, i.e. between time for informal meetings and openness, all variables are in statistically significant relationships. Thus, the results show that positive employee relationships influence the individual commitment to innovations, as it was proved through the hierarchical regression analysis. What is more, positive relationships determine internal communication in terms of both its openness and practicing informal meetings in an organization which supports Hypothesis 3 . It is a very important conclusion as internal communication has been approved as a factor of organizational innovativeness. Our research demonstrates that positive employee relationships may perform a key role in the whole process.

\section{Discussion}

The process of innovation creation within an organization is based on the search for the new information and knowledge to come up with novel solutions, processes, products or ideas.
This search is a human capability facilitated not only by organizational systems, incentives and processes, but most of all by organizational climate, including internal communication and interpersonal relationships within organization. Our study contributes to the research stream revealing mechanisms and causal relations among innovation climate dimensions.

In the proposed model we show that positive relationships at work (PRW) should be considered among prerequisites of innovation creation in an organization. They are directly linked to the individual commitment to innovations as well as influence internal communication facets supporting organizational innovativeness. Such a direction of dependency in our model has been assumed on the basis of PRW research stream and approved with our study results. At the same time we are aware that relationships among analyzed phenomena may be mutual, thus the problem has to be discussed in this paragraph.

Positive relationships at work are among the main issues investigated within the umbrella concept of Positive Organizational Scholarship (POS) (Cameron, Dutton, \& Quinn, 2003; Cameron \& Spreizer, 2012). Seeking 
for phenomena responsible for organizational flourishing and prosperity (as opposite to just a standard or 'normal' performance) POS considers positive relationships at work as an antecedent of generative processes occurring in the organization. We adopt this perspective in our study and examine PRW as a factor of organizational innovativeness, treating them as a key factor of innovation climate. Following this path, we demonstrate that positive relationships at work shape also the aspects of internal communication that are related to the innovation climate dimensions. This finding is consistent with an observation that positive relationships at work include, inter alia, a dimension of emotional carrying capacity (Dutton \& Heaphy, 2003). This is the extent to which the relationship comprises (and can survive) expressing the whole range of different positive and negative emotions (Ragins \& Dutton, 2007). The higher relationship 'positivity', the stronger its emotional carrying capacity. Positive relationships give the relationship partners the ability to survive a greater number of diverse expressions. This implies that in teams, which build positive interpersonal relationships of the members, communication is more open and includes expression of both positive and negative information.

Simultaneously, there is strong evidence showing that communication influences interpersonal relationships at work. Effective communication is a prerequisite for fulfilling relationships (Alexander, 1973; Cushman \& Cahn, 1985; Murstein, 1977), while ineffective communication can lead to problems of individuals within their social relations (Collins, 2003; Erven, 2012; Burtis \& Turman, 2005; Brounstein, 2001; Weaver \& Hybels, 2008). Particularly, manager attitudes and patterns of behavior manifested in the communication process play a crucial role in shaping employee relationships in teams.

The two aforementioned perspectives may be reconciled with a help of the 'positive upward spiral' concept elaborated in the field of POS (Fredrickson, 2003). This is the continuum of interdependent relations among positive organizational phenomena and processes. The analysis of the process may start in any point i.e. from the positive emotions experienced by employees involved in positive relationships at work. Such emotions generate positive energy which motivates employees to engage in reaching outstanding outcomes, continuous improvement, broadening their cognitive horizons. It may result in more open internal communication which supports innovative solution creation and facilitates both personal goals achievements and the development of an organization (Roberts, 2007). The efficiency and success of the organization give satisfaction to employees, which strengthens their bounds and release positive emotions, and at this point the next loop of a positive upward spiral begins. As the result, in 'the next loop' positive relationships at work are influenced, in fact, by open internal communication supporting innovation creation that, in turn, arouse positive emotions and interpersonal relations.

Regardless of the truthfulness of the 'positive upward spiral', the results of our survey show that the role of positive relationships at work is very special in this process. The hierarchical regression analysis showed that PRW serve as a better predictor of employee commitment to innovations than communication facets. And although our analysis has not proven that PRW influence communication stronger than communication influences relationships at work we propose to treat PRW as the prerequisite of the whole process. Arguments supporting such a belief seem stronger. Positive relationships among employees are perceived as the foundation for common learning, efficient communication and trust, necessary to generate creative ideas and process them critically (Drah-Zahavy \& Somech, 2013). Positive relationships at work create an emotional safety, employees are more open to learn from each other and change the way of doing things, they trust each other more and communicate more frequently and more honestly (Davidson \& James, 2007; Roberts, 2007). Finding a secure base for learning and experimenting employees are able to consider failures, criticism and negative feedback as opportunities to learn and improve (Roberts, 2007). Thus PRW support the constructive exchange of critical feedback while the opposite, i.e. triggering relationship positivity through open exchange of all opinions, good and bad, is rather doubtful.

According to data presented in this paper, the relation between PRW and individual commitment to innovation is linear. A curvilinear effect appeared non-significant. However, the 'shape' of this effect is very 
interesting and we treat it as an inspiration for further studies. Specifically, it suggests that negative (less positive) relationships at work may be more advantageous for an organization than the middling, and only distinctly positive relationships clearly support individual commitment to innovations. The shape of this relation contributes thus to the discussion concerning positive versus negative effects of PRW. The negative side of positive relationships at work is associated, for instance, with a notion that positive connections may evolve into friendships being a source of distraction during working-hours (O'Conaill \& Frohlich, 1995). Generally supporting employee wellbeing, positive relationships at work may decrease concentration on tasks and create a distance to work. Some managers consider friendships at work as threats and sources of gossip or favoritism (Berman et al., 2002). The only positive effect of PRW is also doubted on the ground of the behavioral theory of corporate governance (Westphal \& Zajac, 2013). According to it, decision-makers are influenced by their social relations, particularly by the closest ones, and due to that fact their decisions are biased. On the other hand, flattering or conformity of people with whom the decision-makers are in positive relationships lead to their overconfidence and significantly decrease a chance for rational decisions. Similar effects are reported concerning creative work, i.e. because of their positive relationships with co-workers individuals may be distracted and unwilling to recognize opinions and ideas of wider network of people (Shalley, 1995; PerrySmith \& Shalley, 2003). Our analysis suggests, however, that this effect is not present when relationships are truly positive but, presumably, may appear in case of mid-positive relationships. We propose to label this effect as 'relationship bogged down effect'. It means that both positive and negative relationships motivate employees to greater commitment (although the stimulating effect of positive relationships is much stronger), while in the case of employees involved in 'medium-positive' relationships their organizational commitment is relatively lower. Assuming that the curvilinear relationship may be proved by a study on another sample, it would be interesting to explain which variables may explain the 'bogged down effect'.

Additionally our research contributes to a discussion concerning advantages of informal meetings during working-hours. Very few surveys have been conducted in this field but most of them proved a positive effect of such gatherings (Mangrum, 2002). In our approach we did not specify the kind of informal meetings, while it is crucial for further investigations. Notably, the positive effect of so called 'focused gatherings', i.e. informal problem solving meetings, has been reported. They refer to a tendency of employees to gather in a huddle near someone's desk, in hallways, in aisles etc. to deal with job-related issues. They solicit or deliver information, make decisions or simply seek knowledge or opinions from others to confirm or reinforce their own ideas about a decision to be made at a later time. Our analysis shows that allowing the employees to have time for informal meeting during their working-hours may contribute to the individual commitment to innovations. We predict that during informal gathering employees talk mostly about their work and an exchange of opinions and problems they notice in organizational settings may inspire for ideas evolving into innovations.

\section{Conclusions, Practical Implications and Limitations of the Study}

The main conclusion and the practical implication of this study refers to the importance of positive relationships at work (PRW) stimulation in an organization. Our research demonstrates that they should be considered among factors shaping such critical organizational processes as communication and innovativeness. And as such they should be built and carefully maintained in every organization. Although PRW creation is not an easy pursuit and requires particularly great and consistent efforts on managerial part, it seems still that this action may be more efficient than, for instance, initiating open communication and debate climate, which are inhibited by many social aspects in the organization.

Among implications of our study as well as issues inspiring for further studies we point out also the need for allowing employees to gather informally during their working-hours. This is an important conclusion, particularly facing the fact that some modern management concepts and tendencies, e.g. lean-management, downsizing, e-work, lead to a reduction of time that employee can spend on spontaneous meetings. 
We are aware of the limitations of our study. The collected data illustrating the links between the positive relationships within employee teams and their capability to create innovations is based on assessments, or diagnoses, by a selected employee of the organization. Despite the fact that we attempted to conduct the interview each time with a person who can offer the necessary review of the processes inside the company, because of their responsibilities, there is a risk that the person has presented a subjective picture of the organization, perceived the internal relationships or the conditions for the processes of creating innovations only through the prism of their own individual experiences (perhaps short-sighted ones, based on an unsatisfactory scope of observations available to the respondents), and which potentially may not be representative. Moreover, we are aware that the subject matter (innovations, relationships at work, communication patterns) 'promotes' the subjectivity of opinions, may be interpreted, or assessed in various ways etc. However, it is worth emphasizing that the sample of respondents was selected purposively, i.e. the sample was composed of persons with various functions within the enterprise but having access to knowledge on innovation creation process. Anyway, this study inspires for in-depth investigations, not only with a use of quantitative methods, but possibly based on ethnographic studies using the technique of free-form interview, participatory observation or focus group interviews with the employees.

The project was funded by the Polish National Science Centre grant on the decision number DEC-2013/11/B/HS4/00691.

\section{References}

Abeyrathne, H.R.M.P., \& Jayawardena, L.N.A.C. (2014). Impact of Group Interactions on Farmers' Entrepreneurial Behaviour. E\&M Ekonomie a Management. 17(4), 46-57. doi:10.15240/tul/001/2014-4-004.

Agrell, A., \& Gustafson, R. (1996). Innovation and creativity in work groups. In M. A. West (Ed.), Handbook of work group psychology (pp. 314-343). London: Wiley.

Aiken, M., \& Hage, J. (1971). The organic organization and innovation. Sociology, 5, 63-82.
Alexander, J. F., \& Parsons, B. V. (1973). Short-term Behavioral Intervention with Delinquent Families: Impact on Family Process and Recidivism. Journal of Abnormal Psychology, 81(3), 219-225.

Anderson, N. R., \& West, M. A. (1998). Measuring Climate for Work Group Innovation: Development and Vallidation of the Team Climate Inventory. Journal of Organizational Behaviour, 19(3), 235-268. doi:10.1002/ (SICI)1099-1379(199805)19:3<235::AIDJOB837>3.0.CO;2-C.

Aydin, B., \& Ceylan, C. (2009). The Role of Organizational Culture on Effectiveness. E\&M Ekonomie a Management, 12(3), 33-49.

Baregheh, A., Rowley, J., \& Sambrook, S. (2009). Towards a multidisciplinary definition of innovation. Management Decision, 47(8), 1323-1339. doi:10.1108/00251740910984578.

Berman, E. M., West, J. P., \& Richter, M. N. (2002). Workplace Relations: Friendship Patterns and Consequences (according to managers). Public Administration Review, 62(2), 217-230. doi:10.1111/0033-3352.00172.

Bessant, J., Lamming, R., Noke, H., \& Philips, W. (2005). Managing innovations beyond the steady state. Technovation, 25(12), 1366-1376. doi:10.1016/j.technovation.2005.04.007.

Bessant, J., \& Tidd, J. (2007). Innovation and Entrepreneurship. Chichester: Wiley.

Bono, J. E., \& Yoon, D. J. (2012). Positive Supervisory Reelationships. In L. Turner de Tormes Eby \& T. D. Allen (Eds.), Personal Relationships. The Effect on Employee Attitudes, Behavior, and Well-being (pp. 43-66). New York: Routledge.

Bradbury, H., \& Lichtenstein, B. M. B. (2000). Relationality in Organizational Research: Exploring The Space Between. Organization Science, 11(5), 551-564. doi:10.1287/orsc.11.5.551.15203.

Brounstein, M. (2001). Communicating Effectively for Dummies. New York: Wiley Publishing.

Brown, T. E., \& Ulijn, J. M. (2004). Innovation, entrepreneurship and culture, a matter of interaction between technology, progress and economic growth? An Introduction. In T. E. Brown, \& J. M. Ulijn (Eds.), Innovation, entrepreneurship and culture, a matter of interaction between technology, progress and economic growth (pp. 1-38). Northampton: Edward Elgar.

Burke, W. W., \& Litwin G. H. (1992). A casual model of organizational performance 
and change. Journal of Management, 18(3), 523-545. doi:10.1177/014920639201800306.

Burtis, J. O., \& Turman, P. D. (2005). Group Communication Pitfalls: Overcoming Barriers to an Effective Group Experience. New York: Sage Publications.

Cameron, K. S., \& Spreitzer, G. M. (Eds.). (2012). The Oxford Handbook of Positive Organizational Scholarship. New York: Oxford University Press.

Cameron, K. S., Dutton, J. E., \& Quinn, R. E. (Eds.). (2003). Positive Organizational Scholarship. Foundation of a New Discipline. San Francisco: Berrett-Koehler Publishers, Inc.

Carmeli, A., Brueller, D., \& Dutton, J. E. (2009). Learning behaviours in the workplace: The role of high-quality interpersonal relationships and psychological safety. Systems Research and Behavioral Science, 26(1), 81-98. doi:10.1002/sres.932.

Chen, G., \& Sharma, P. N. (2012). Bringing Together the Yin and Yang of Social Exchanges in Teams. In L. Turner de Tormes Eby, \& T. D. Allen (Eds.), Personal Relationships. The Effect on Employee Attitudes, Behavior, and Wellbeing (pp. 221-234). New York: Routledge.

Chiaburu, D. S., \& Harrison, D. A. (2008). Do Peers Make the Place? Conceptual Synthesis and Meta-Analysis of Co-Worker Effects on Perceptions, Attitudes, OCBs, and Performance. Journal of Applied Psychology, 93(5), 1082-1104. doi:10.1037/0021-9010.93.5.1082.

Collins, K. (2003). Penetrating Barriers. Communication World, June-July, 26-30.

Colquitt, J. A., Scott, B. A., \& LePine, J. A. (2007). Trust, Trustworthiness and Trust Propensity: A Meta-Analytic Test of Their Unique Relationships With Risk Taking and Job Performance. Journal of Applied Psychology, 92(4), 909-927. doi:10.1037/00219010.92.4.909.

Cushman, D. P., \& Cahn, D. D. Jr. (1985). Communication in Interpersonal Relationships. New York: State University of New York Press.

Damanpour, F. (1991). Organizational innovation: a meta-analysis of effects of determinants and moderators. Academy of Management Journal, 34(3), 555-590. doi:10.2307/256406.

Damanpour, F. (1996). Organizational complexity and innovation: developing and testing multiple contingency models. Management Science, 42(5), 693-716. doi:10.1287/mnsc.42.5.693.
Davidson, M. N., \& James E. H. (2007). The Engines of Positive Relationships Across Difference: Conflict and Learning. In J. E. Dutton, \& B. R. Ragins (Eds.), Exploring Positive Relationships at Work: Building a Theoretical and Research Foundation (pp. 137-158). New York: Lawrence Erlbaum.

DeChurch, L. A., \& Marks, M. A. (2001). Maximizing the benefit of task conflict: The role of conflict management. International Journal of Conflict Management, 12(1), 4-22. doi:10.1108/eb022847.

De Dreu, K. W. (2006). When Too Little or Too Much Hurts: Evidence for a Curvilinear Relationship Between Task Conflict and Innovation in Teams. Journal of Management, 32(1), 83-107. doi:10.1177/0149206305277795.

De Dreu, C. K. W., \& Weingart, L. R. (2003). Task versus relationship conflict, team effectiveness, and team member satisfaction: A meta-analysis. Journal of Applied Psychology, 88(4), 741-749. doi:10.1037/00219010.88.4.741.

Dirks, K. T., \& Ferrin, D. L. (2002). Trust in Leadership: Meta-analytic Findings and Implications for Research and Practice. Journal of Applied Psychology, 87(4), 611-628.

Drah-Zahavy, A., \& Somech, A. (2001). Understanding team innovation: The role of team processes and structures. Group Dynamic Theory, 5(2), 111-123. doi:10.1037//10892699.5.2.111.

Drah-Zahavy, A., \& Somech, A. (2013). Translating Team Creativity to Innovation Implementation: The Role of Team Composition and Climate for Innovation. Journal of Management, 39(3), 684-708. doi:10.1177/0149206310394187.

Dutton, J. E., \& Heaphy, E. D. (2003). The Power of High-Quality Connections. In K. S. Cameron, J. E. Dutton, \& R. E. Quinn (Eds.), Positive Organizational Scholarship. Foundation of a New Discipline (pp. 263-278). San Francisco: Berrett-Koehler Publishers, Inc.

Dutton, J. E., \& Ragins, B. R. (Eds.). (2007). Exploring Positive Relationships at Work: Building a Theoretical and Research Foundation. New York: Lawrence Erlbaum.

Ekvall, G. (1996). Organizational climate for creativity and innovation. European Journal of Work and Organizational Psychology, 5, 105-123. doi:10.1080/13594329608414845.

Ellonen, R., Blomqvist, K., \& Puumalainen, K. (2008). The role of trust in organizational 
innovativeness. European Journal of Innovation Management, 11(2), 160-181. doi:10.1108/14601060810869848.

Erven, B. L. (2012). Overcoming Barriers to Communication. Retrieved April 24, 2015, from http://aede.ag.ohio-state.edu/people/erven.1/ HRM/communication.pdf.

Fredrickson, B. L. (2003). Positive Emotions and Upward Spirals in Organizations. In K. S. Cameron, J. E. Dutton, \& R. E. Quinn (Eds.), Positive Organizational Scholarship: Foundation of a New Discipline (pp. 163-173). San Francisco: Berrett-Koehler Publishers.

Gorse, C. A., \& Emmitt, S. (2009). Informal interaction in construction progress meetings. Construction Management and Economics, 27(10), 983-993. doi:10.1080/01446190903179710.

Grant, A. R., \& Parker, S. K. (2009). Redesigning Work Design Theories: The Rise of Relational and Proactive Perspectives. Academy of Management Annals, 3(1), 317-375. doi:10.1080/19416520903047327.

Halbesleben, J. R. B. (2012). Positive Coworker Exchanges. In L. Turner de Tormes Eby, \& T. D. Allen (Eds.), Personal Relationships. The Effect on Employee Attitudes, Behavior, and Well-being (pp. 107-130). New York: Routledge.

Hardin, R. (2006). Trust. Cambridge: Polity Press.

Holá, J. (2012). Internal Communication in the Small and Medium Sized Enterprises. E\&M Ekonomie a Management, 15(3), 32-45.

Hunter, S. T., Bedell, K. E., \& Mumford, M. D. (2007). Climate for Creativity: A Quantitative Review. Creativity Research Journal, 19(1), 6990. doi:10.1080/10400410709336883.

Ibarra, H. (1993). Personal Networks of Women and Minorities in Management: A Conceptual Framework. Academy of Management Review, 18(1), 56-87. doi:10.5465/AMR.1993.3997507.

Isaksen, S. G., \& Ekvall, G. (2010). Managing for Innovation: The Two Faces of Tension in Creative Climates. Creativity and Innovation Management, 19(2), 73-88. doi:10.1111/j.1467-8691.2010.00558.x.

Isaksen, S. G., Lauer, K. J., Ekvall, G., \& Britz, A. (2001). Perceptions of the Best and Worst Climates for Creativity: Preliminary Validation Evidence for Situational Outlook Questionnaire. Creativity Research Journal, 13(2), 171-184. doi:10.1207/S15326934CRJ1302_5.
Kahn, W.A. (1990). Psychological Conditions of Personal Engagement and Disengagement at Work. Academy of Management Journal, 33(4), 692-724. doi:10.2307/256287.

Kram, K. E., \& Isabella, L. A. (1985). Mentoring Alternatives: The Role of Peer Relationships in Career Development. Academy of Management Journal, 28(1), 110132. doi: $10.2307 / 256064$.

Leenders, R. T. A., Van Engelen, J. M., \& Kratzer, J. (2003). Virtuality, communication and new product team creativity: a social network perspective. Journal of Engineering and Technology Management, 20(1-2), 69-92. doi:10.1016/S0923-4748(03)00005-5.

Lewicki, R. J., \& Bunker, B. B. (1996). Developing and Maintaining Trust in Work Relationships. In R. M. Kramer, \& T. R. Tyler (Eds.), Trust in Organizations: Frontiers of Theory and Research (pp. 114-139). Thousand Oaks: Sage Publications.

Loewe, P., \& Dominiquini, J. (2006). Overcoming the barriers to effective innovation. Strategy and Leadership, 34(1), 24-31. doi:10.1108/10878570610637858.

Makin, P. J., Cooper, C. L., \& Cox, C. J. (1996). Organizations and Psychological Contract. Leicester: The British Psychological Society.

Mangrum, F. G. (2002). Macro and Micro Features of Informal Meetings: A Theoretical Framework. Paper presented at Annual Meeting of the Central States Communication Association. Retrieved May 15, 2015, from http://www.eric.ed.gov/contentdelivery/servlet/ ERICServlet?accno=ED463519.

McKnight, D. H., \& Chervany, D. H. (1996). The Meaning of Trust. Minneapolis: University of Minnesota.

Mitrović, S., Grubić-Nešić, L., Milisavljević, S., Melović, B., \& Babinková, Z. (2014). Manager's Assessment of Organizational Culture. E\&M Economics and Management, 17(3), 35-49. doi:10.15240/tul/001/2014-3-004.

Mumford, M. D., Hunter, S. T., Eubanks, D. L., Bedell, K., \& Murphy, S. T. (2007). Developing leaders for creative efforts: A domain-based approach to leadership development. Human Resource Management Review, 17(4), 402-417. doi:10.1016/j.hrmr.2007.08.002.

Muñoz-Doyague, M. F., \& Nieto, M. (2012). Individual creativity performance and the quality of interpersonal relationships. Industrial Management \& Data Systems, 112(1), 125-145. doi:10.1108/02635571211193671. 
Murstein, B. I. (1977). The Stimulus-ValueRole (SVR) Theory of Dydic Relationship. In S. Duck (Ed.), Theory and practice in interpersonal attraction (pp. 105-129). London: Academic Press.

Naranjo-Valencia, J. C., Jimenez-Jimenez, D., \& Sanz-Valle, R. (2011). Innovation or imitation? The role of organizational culture. Management Decision, 49(1), 55-72. doi:10.1108/00251741111094437.

Nemeth, C., \& Chiles, C. (1988). Modelling courage: The role of dissent in fostering independence. European Journal of Social Psychology, 18(3), 275-280. doi:10.1002/ejsp.2420180306.

Nonaka, I., \& Takeuchi, H. (1995). The Knowledge-Creating Company: How Japanese Companies Create the Dynamics of Innovation. New York: Oxford University Press.

O'Conaill, B., \& Frohlich, D. (1995). Timespace in the workplace: Dealing with interruptions. Proceedings of CHI'95 Human Factors in Computing Systems (pp. 262-263). New York: ACM Press.

Perry-Smith, J. E., \& Shalley, C. E. (2003). The Social Side of Creativity: A Static and Dynamic Social Network Perspective. Academy of Management Review, 28(1), 89-106. doi:10.5465/AMR.2003.8925236.

Pietrzak, M. B., \& Łapińska, J. (2015). Determinants of the European Union's Trade - Evidence From a Panel Estimation of the Gravity Model. E\&M Ekonomie a Management, 18(1), 18-27. doi:10.15240/tul/001/2015-1-002.

Pirson, M. (2008). Facing the Trust Gap Measuring and Managing Stakeholder Trust. Saarbrucken: SVH.

Plessis, M. D. (2007). The role of knowledge management in innovation. Journal of Knowledge Management, 11(4), 20-29. doi:10.1108/13673270710762684.

Quinn, R. W. (2007). Energizing Others in Work Connections. In J. E. Dutton, \& B. R. Ragins (Eds.), Exploring Positive Relationships at Work: Building a Theoretical and Research Foundation (pp. 73-90). New York: Lawrence Erlbaum.

Ragins, B. R., \& Dutton, J. E. (2007). Positive Relationships at Work: An Introduction and Invitation. In J. E. Dutton, \& B. R. Ragins (Eds.), Exploring Positive Relationships at Work: Building a Theoretical and Research Foundation (pp. 3-25). New York: Lawrence Erlbaum.
Rawlins, W. K. (1992). Friendship Matters: Communication, Dialectics, and the Life Course. Hawthorne, New York: Aldine de Gruyter.

Roberts, L. M. (2007). From Proving to Becoming: How Positive Relationships Create a Context for Self-discovery and Selfactualization. In J. E. Dutton, \& B. R. Ragins (Eds.), Exploring Positive Relationships at Work: Building a Theoretical and Research Foundation (pp. 29-46). New York: Lawrence Erlbaum.

Ross, P. F. (1974). Innovation adoption by organizations. Personnel Psychology, 27, 21-47.

Shalley, C. E. (1995). Effects of coaction, expected evaluation, and goal setting on creativity and productivity. Academy of Management Journal, 38(2), 483-503. doi:10.2307/256689.

Serva, M. A., Fuller, M. A., \& Mayer, R. C. (2005). The Reciprocal Nature of Trust: A Longitudinal Study of Interacting Teams. Journal of Organizational Behaviour, 26(6), 625-648. doi:10.1002/job.331.

Shaw, R. B. (1997). Trust in the Balance: Building Successful Organizations on Results, Integrity and Concern. San Francisco: JosseyBass.

Sökmen, A., Bitmiş, M. G., \& Üner, M. M. (2015). The Mediating Role of PersonOrganization Fit in the Supportive LeadershipOutcome Relationships. E\&M Ekonomie a Management, 18(3), 62-72. doi:10.15240/ tul/001/2015-3-006.

Stephens, J. P., Heaphy, E., \& Dutton, J. E. (2012). High-quality connections. In K. S. Cameron, \& G. M. Spreitzer (Eds.), The Oxford Handbook of Positive Organizational Scholarship (pp. 385-399). New York: Oxford University Press.

Szczepańska-Woszczyna, K. (2014). Innovation process in the social space of the organization. Regional Formation and Development Studies, 14(3), 220-229. doi:10.15181/rfds.v14i3.878.

Turner de Tormes Eby, L., \& Allen, T. D. (Eds.). (2012). Personal Relationships. The Effect on Employee Attitudes, Behavior, and Well-being. New York: Routledge.

Utterback, J. M., \& Abernathy, W. J. (1975). A dynamic model of process and product innovation. Omega, 3(6), 639-656. doi:10.1016/0305-0483(75)90068-7.

Van Offenbeek, M., \& Koopman, P. (1996). Interaction and decision making in project 
teams. In M. A. West (Ed.), Handbook of work group psychology (pp. 159-187). London: Wiley.

West, M. A., \& Farr, J. L. (1990). Innovation at work. In M. A. West, \& J. L. Farr (Eds.), Innovation and creativity at work (pp. 3-13). Chichester: Wiley.

Westphal, J. D., \& Zajac, E. J. (2013). A Behavioral Theory of Corporate Governance: Explicating the Mechanisms of Socially Situated and Socially Constituted Agency. The Academy of Management Annals, 7(1), 607-661. doi:10.1080/19416520.2013.783669.

Wolf, P., Kaudela-Baum, S., \& Meissner, J. O. (2012). Exploring innovating cultures in small and medium-sized enterprises: Findings from Central Switzerland. International Small Business Journal, 30(3), 242-274. doi:10.1177/0266242610386666.

Woodman, R., Sawyer, J. E., \& Griffin, R. W. (1993). Towards a theory of organizational creativity. Academy of Management Review, 18(2), 293-321.

Zhou, J., \& George, J. M. (2001). When job dissatisfaction leads to creativity: encouraging the expression of voice. Academy of Management Journal, 44(4), 682-697. doi:10.2307/3069410. prof. dr hab. Aldona Glińska-Neweś Nicolaus Copernicus University

Faculty of Economic Sciences and Management

Department of Business Excellence ajka@econ.umk.pl

prof. dr hab. Agata Sudolska Nicolaus Copernicus University Faculty of Economic Sciences and Management

Department of Enterprise Management aga@econ.umk.pl

prof. dr hab. Arkadiusz Karwacki Nicolaus Copernicus University Faculty of Humanities Institute of Sociology arkadiusz.karwacki@umk.pl

prof. dr hab. Joanna Górka Nicolaus Copernicus University Faculty of Economic Sciences and Management

Department of Econometrics and Statistics joanna.gorka@umk.pl 


\title{
Abstract
}

\section{INNOVATIONS AMONG PEOPLE. HOW POSITIVE RELATIONSHIPS AT WORK CAN TRIGGER INNOVATION CREATION}

\author{
Aldona Glińska-Neweś, Agata Sudolska, Arkadiusz Karwacki, Joanna Górka
}

Innovations are the essence of the successful organization. The process of their creation is strongly based on individual and team commitment to create improvements in every organizational area. This commitment is triggered by innovation climate including employee positive relationships (PRW) and supporting internal communication facets. The aim of the paper is to define causal relations among the aforementioned variables. We hypothesize that positive relationships at work are a prerequisite of the innovation creation process, i.e. they stimulate employee commitment to innovation creation regardless of the employee position in an organization as well as influence internal communication facets that support innovativeness. Notably, among internal communication elements we analyze open communication of both good and bad information and employee informal meetings. The analyses are based on the quantitative survey conducted on the sample of 200 Polish companies representing various sectors and selected from rankings of the most dynamically developing organizations in Central Europe. In each company we obtained information from a person involved in leading a team creating innovations, i.e. representing different functional departments. In the course of data analyses we used the hierarchical regression and the linear regression analysis. The results support the hypotheses of PRW key role in the innovativeness process, and the effect appeared to be linear. Specifically, positive relationships at work stimulate both employee individual commitment to innovations and internal communication supporting innovativeness. These findings contribute to the research stream connected with the Positive Organizational Scholarship umbrella concept. Practical implications of the survey point to the need of positive relationships at work stimulation in organizations.

Key Words: Innovation, innovation creation, positive relationships at work, internal communication.

JEL Classification: 031, J29, D23.

DOI: 10.15240/tul/001/2017-3-006 